\title{
Between English and Esperanto: what does it take to be a world language?'
}

DAVID C. S. LI

Abstract

English has emerged as a world language after the Second World War. This role of English as a de facto international lingua franca has been criticized as 'linguistic imperialism' or 'linguicism', threatening the vitality and development of many local languages in former Anglo-American colonies, especially in Africa and Asia. To counter the hegemony of the phenomenal spread of English worldwide, some scholars advocate and promote the use of Esperanto, an artificial language, as an international auxiliary language. Created by Lazaro Ludoviko Zamenhof in 1887, Esperanto is largely based on the lexicons of several dominant European languages, an alphabetical language characterized by a learner-friendly phonology and relatively simple syntax and morphology. To adherents of Esperanto, its sociolinguistic appeal lies mainly in the fact that, unlike English, it is no one's first language, and so no user of Esperanto would feel disadvantaged when communicating with other fellow Esperantists. After over 110 years of continual development, the Esperanto movement has attracted thousands of followers worldwide, but toward the goal of replacing English as a world language, Esperanto faces many obstacles. This paper discusses two main problems confronted by Esperanto as a serious contender of English for that role: relatively limited communicative functions, and the 'medium-as-message' paradox. These problems explain why individual language learners find Esperanto unattractive compared to other natural languages of wider communication, and why governments tend to lack the incentive to add Esperanto to the local school curriculum. The claim that the spread of English is responsible for the world's social evils is overstated. Globalization is more satisfactorily accounted for by the global triumph of the 'Utilitarian Discourse System.'

\section{Introduction}

For historical reasons, since the end of the Second World War English has emerged as a de facto world language ${ }^{2}$ in the international arena, especially 
between people whose first language is one other than English. The role of English as an international lingua franca, however, has met with severe criticism on the part of some scholars, who see in the phenomenal spread of English a form of hegemonic control and 'linguistic imperialism,' or 'linguicism' (Skutnabb-Kangas and Phillipson 1986; Phillipson 1992) in the post-colonial era, threatening the vitality and stifling the development of local languages, especially in post-colonial societies in Africa and Asia. The hegemonic influence of English is manifested in a number of domains of language use, ranging from international business to academic conferences, from advertising to language education. Among the most outspoken critics of this view are Robert Phillipson (1992, 1994, 1997, 1998, 2000, 2001a, 2001b) and Tove Skutnabb-Kangas (2000). One major criticism of the spread of English is the cultural and linguistic penetration of the 'Periphery' by 'Centre' countries, notably the U.K. and the U.S.A., often disguised in the form of some economic aid package. Phillipson argues that this is a form of imperialism, 'English linguistic imperialism': "the dominance of English is asserted and maintained by the establishment and continuous reconstitution of structural and cultural inequalities between English and other languages" (Phillipson 1992: 47). According to Phillipson, there are three phases of colonialism. A subtle hegemonic control is realized in the third phase called 'neo-neo-colonialism,' whereby the exploiters need not be present and where there is widespread belief among former colonial subjects that English is useful and good for them. This is what makes English language teaching (ELT) such a lucrative business, a multimillion-dollar enterprise which is probably more precious than North Sea oil (Skutnabb-Kangas 2000; cf. Pennycook 1994, 1998).

Phillipson's (1992) book has given rise to much debate about the functions and status of English in post-colonial societies. A colloquium entitled 'Partnership and patronage in ELT development' was organized at the 26th TESOL convention in Vancouver in 1992. This was followed by a symposium on linguistic imperialism contributed by six scholars, including Phillipson's own response (see World Englishes, 1993, vol. 12, no.3, pp. 336-373). The book has also received a number of reviews in various journals subsequently. Of interest to us here is the observation that, while practically all teachers of English, whatever their first-language background, are implicated in their professional role as agents assisting in the perpetuation of the global hegemony of English, sympathetic readers, notably teachers of English, are at a loss as to what they can or should do to help alleviate their enhanced awareness and newly acquired sense of guilty conscience (Berns et al. 1998, 1999). Phillipson seemed to have acknowledged such a lacuna, which is probably why he looked to Esperanto as a likely candidate to substitute for English as an international auxiliary language. 
The paper will first outline the background against which the present author was attracted to the study of Esperanto with regard to its history and its prospects as an international auxiliary language. It will then briefly examine the Esperanto movement in China before discussing two major problems confronted by the international Esperanto movement, namely, the 'function-before-structure' principle, and the 'medium-as-message' paradox. The role of English as a world language will be assessed using a supply-cum-demand analysis. It will be argued that the international Esperanto movement suffers from a catch 22 kind of problem: it is difficult to raise the number of Esperanto learners to a critical mass, not until it is perceived as a 'useful' and 'practical' second language serving a broad range of communicative functions in a great variety of communicative settings. At the same time, so long as the Esperanto community remains small, Esperanto learners have little impetus to use Esperanto - either in place of or in addition to other languages of wider communicationvoluntarily for creative purposes such as literary, artistic, and academic writing. Until the catch is resolved, Esperantists will continue to be fighting an uphill battle vis-à-vis its arch rival, English. Finally, we will discuss one attribution problem: it will be argued that if globalization is the source of many social evils, it is driven not so much by the phenomenal spread of English as the global triumph of the 'Utilitarian Discourse System' (Scollon and Scollon 1995).

\section{Why Esperanto?}

In fall 1999, in a keynote speech given at the Second International Conference on Major Varieties of English (MAVEN 2): 'The English Language Today: Functions and Representations' which took place in Lincoln, U.K., Prof. Robert Phillipson began with the questions (my gloss) "Are there any Esperantists in the audience?", "Is there anyone who has attended the World Congress of Esperanto before?" From what I recall, very few, if any, in the audience raised their hands to either of these questions. At that time, I had no idea what the connection was between Esperanto and the main theme of the conference. In retrospect, I think Esperanto might have caught Phillipson's attention, because he sees in it a likely solution to overcoming a widely perceived dilemma: on the one hand, the need for an international lingua franca as a result of everexpanding communication across language and ethnic boundaries, and on the other hand, an acute dissatisfaction with English being assigned that role. Advocates of Esperanto believe that there are at least three reasons why English is unsuited for that role (Hou and Zhou 1999: 11f.): 
(a) The spread of English worldwide is largely the result of centuries of British and American empire building, conquest, and colonization, and more recently, the American dominance of international politics, business, and media. As an ethnic language, English came to play that role neither through consensus nor popular choice, resulting in inequality among natural languages and discrimination of minority languages. This is especially evident in former British and American colonies (cf. Phillipson 1992).

(b) Accepting English as an international language is tantamount to legitimating and intensifying the hegemonic control of those powers where English is used as L1.

(c) In linguistic terms, the use of English as an international lingua franca is problematic because of tremendous variability and regional differences even within the English L1 countries (cf. 'Inner Circle,' Kachru 1985, 1996).

At the same time, there are several closely related reasons why Esperanto, a planned language, ${ }^{3}$ is seen as much more suitable than English for the role of an international auxiliary language. First, it is by design no one's mother tongue. As Tonkin (1987: 266) remarks, "Zamenhof's motives in creating Esperanto were primarily moral and idealistic, rather than economic and linguistic." Since its inception when Zamenhof published the booklet Lingvo Internacia under the pseudonym 'Doktoro Esperanto' in 1887, Esperanto (literally 'one who hopes') is intended to be an auxiliary language facilitating interethnic encounters in international settings, which makes it an ideal choice for a non-hegemonic language of wider communication. Second, as a correlate of the first point, since Esperanto is nobody's mother tongue, no one is at a disadvantage vis-à-vis their interlocutors by using it as an auxiliary language, which is essentially why communication between Esperantist interlocutors is said to be more egalitarian. Third, since Esperanto is not imposed in any educational system but learned more often than not for ideological reasons by individuals from different linguistic backgrounds who make up a "voluntary, nonethnic, non-territorial speech community" (Wood 1979), Esperantists tend to perceive each other as members of the same Gemeinschaft community, ideological partners or comrades, which helps explain why communication between them tends to be pervaded with a strong sense of communion and solidarity (Forster 1982; Piron 1989; Edwards 1993). Fourth, as mentioned in most of the studies on Esperanto, especially introductory grammars, unlike scores of other artificial languages, Esperanto is relatively easy to learn, for one of its key design features is simplicity in practically all its linguistic subsystems, which may be summarized as follows (cf. D. Blanke 1989: 79-80): ${ }^{4}$ 
- Phonetics and phonology: a simple phonological system free from difficult phonemes such as English $\mid \theta /$, and a highly regular stress pattern (stress is placed consistently on the penultimate syllable of a polysyllabic word) make for easy pronunciation.

- Orthography: 28 letters, six of which with diacritics; the spelling is completely phonetic, that is, one letter one sound.

- Vocabulary: exceptionless agglutinative morphology allows for easy recognition of word class membership and the easy derivation of semantically related lexical items (e.g. viro 'man', virino 'woman'; bovo 'bull', bovino 'cow', bovido 'little cow or cub'; kiko 'hen', kikido 'chick'; vorto 'word', vortaro 'dictionary'; arbo 'tree', arbaro 'forest'; boto 'boot', botisto 'cobbler'; lingvo 'language', lingvisto 'linguist'); only when words cannot be found in any major natural languages will special coinage be considered.

- Syntax: free word order; and a finite set of sixteen syntactic rules. ${ }^{5}$

Thanks to these linguistic features, the textual comprehension and production of Esperanto are relatively straightforward tasks. Consequently, there is much truth in the claim that the time it takes to master Esperanto is shorter compared with the task of learning English as a second or foreign language. Indeed, the argument is often made that, since a lifetime is too short for developing native-like competence in a foreign language, Esperanto would be a much more sensible choice than an unplanned, ethnic language like English. In addition, since Esperanto is an alphabetical language with its inventory of lexical items drawn largely from IndoEuropean, notably Romance, Germanic, and Slavic languages (e.g. Latin, French, English, German, Polish, and Russian; see Tonkin 1987: 267; Hou and Zhou 1999: 26), it has been pointed out that prior knowledge of Esperanto can facilitate the learning of any European language subsequently (Large 1985: 126; cf. Hou 1999; Hou and Zhou 1999). Another area of application where Esperanto has great potential to contribute to international communication is translation, including machine translation and terminological standardization (W. Blanke 1989; Sadler 1989). Further, in times of great communication barriers such as the period of the Cold War, Esperanto served an admirable cause. As Tonkin (1993: 11) remarks, "[n]o history of human contacts during the Cold War should ignore the role of Esperanto, though that history has still to be written." The institutional goal of Esperanto as a language of wider communication won the recognition and support of UNESCO in 1954, whose main objective is to promote international understanding and to facilitate cultural exchange among different races of member states of the UN (Forster 1982; Humblet 1984; Large 1985). 
All the merits mentioned above clearly have positive implications in the domains of education and international communication in terms of economy of time and resources, especially if the number of people literate and conversant in Esperanto has reached a critical mass. For example, it has been estimated that much language learning time could be saved, and the time thus saved could be put to meaningful use, such as helping children to deepen select areas of knowledge or develop certain practical skills (Richmond 1993b); while at international meetings and conferences, a great deal of expenses entailed by the need to make available translations of otherwise mutually unintelligible texts would be significantly reduced (Humblet 1984). This pragmatic function of Esperanto, for example, was greatly valued by the People's Republic during the Cold War period between China and the Soviet bloc in the 1950s: as it was clearly impractical to publish and distribute Chinese cultural materials in every Eastern European language, Esperanto was an efficient and reliable language for disseminating information about new China to readers in Eastern Europe. According to Hou and Zhou (1999: 127), the Esperanto version of Renmin Zhongguo baodao ( 人民中國報導 'People's China Report') was first published in May 1950. Renamed as Zhongguo baodao (中國報導 'China Report') in the early 1970s, this journal represented an important channel through which the Chinese government introduced to the outside world, notably communist states east of the Iron Curtain, various aspects of new China such as political and social development, history and civilization, natural scenery, everyday life of Chinese peoples, and traditions and customs of minority groups (cf. Forster 1982: 257).

The merits of Esperanto noted above are all valid; indeed, it is very difficult to disagree with or challenge Esperantists on their homeground, that is, with regard to Esperanto as an internally coherent and adequate linguistic system on a par with other natural languages. One could perhaps bring up the notion of 'language distance' (Odlin 1989) and argue that speakers of European languages tend to have an advantage learning Esperanto compared with, say, speakers of a typologically distant language like Mandarin Chinese (cf. Large 1985: 185f.). If Esperanto is Eurocentric, the same holds true - and much more so - for a target language like English, which is considerably more complex with regard to all its linguistic subsystems. An optimistic estimate suggests that for speakers of an Asian language, it takes no more than one year of intensive study to reach communicative competence in Esperanto, whereas for speakers of a European language, that same level of competence may be attained within about six months (Hou and Zhou 1999). Further, the notorious problems of dialects - geographical or social - presenting communication problems to L1 or L2 speakers of English are generally denied by leading Esperantists, 
although considerable dialectal variation does occur in the spoken Esperanto of speakers coming from different L1 backgrounds (Braj Kachru, personal communication). In fact, the problem of dialectal variation was detected as early as the First Universala Kongreso held in Boulognesur-mer, France, in 1905, where it was noted that "[a] number of national variations in pronunciation were ... apparent, and at one meeting Zamenhof answered participants' queries on pronunciation and demonstrated the correct usage" (Forster 1982: 88). Esperantists, however, do acknowledge a problem, albeit a minor one in their view. In an interview with English Today, Arnold Pitt, then editor of Esperanto Teacher, pointed out that the meaning of a word may be affected by the speaker's native culture:

Dialects [in Esperanto] are minimal although national culture affects meaning. Demokrata ('democratic') means something entirely different in East and West. Accents are influenced by first languages and first dialects but they are less marked than in an ethnic language. A Glaswegian friend tells me he cannot understand a Cockney colleague in English but understands him perfectly in Esperanto. (The planned and the ethnic 1987: 18f.)

Pitt concludes the interview with the following remark:

Esperanto is an international language actually designed for the job and English is a fine ethnic language pressed into a service for which it is not suited. Latin was the horse-buggy of world languages, English is the steam train and Esperanto will be the jet aircraft. Which would you travel the world by? (The planned and the ethnic 1987: 19)

I think enough has been said above for the Esperanto movement to be characterized as a noble cause. To its supporters, Esperanto is an egalitarian alternative to English. It is looked upon as a tool with which to counter 'linguicism' or 'linguistic imperialism,' a means toward the end of what may be termed 'linguistic utopianism,' an envisioned state of human coexistence in a world free from linguistic injustice and inequality, in which linguistic diversity - coupled with biodiversity - characterized by the equal and peaceful coexistence of discrete varieties of languages and their speakers is the natural order of the day. ${ }^{6}$ One advocate of Esperanto goes so far as to claim that:

$[\mathrm{O}]$ nly an artificial language can prevent the stranglehold of one language over another with all its economic and cultural consequences.

With the possible exception of English-speaking communities, all other nations and speakers of other languages will benefit from the creation of a neutral artificial language. Contrary to what is all too frequently claimed, this is the only reliable 
way of safeguarding specific, geographically limited cultures, as for example Catalan, or cultures such as French that once enjoyed and still enjoy considerable prominence. (Humblet 1984: 154)

This utopian ideal clearly has some ideological affinity with Marxism and socialism, ${ }^{7}$ which helps explain why Esperanto has won the hearts and minds of many mainland Chinese intellectuals (Hou 1999; Hou and Zhou 1999; Liu 1998). Below we will briefly outline the historical development of the Esperanto movement in China. According to Hujucz, New China is probably the only national government in the world which has had an unmistakable penchant for Esperanto and is keen on promoting it (Hou and Zhou 1999: 81), albeit keeping a low profile.

\section{The Esperanto movement in China}

For over a hundred years, Esperanto has had a strong appeal among mainland Chinese intellectuals. The Esperanto movement in China is nearly as old as the Chinese Communist Party (CCP) itself and is characterized by a strong sense of nationalism, internationalism and utopianism (Hou and Zhou 1999). Liu (1998: 76) points out that the early efforts "were associated with the Chinese-language reform movement, whose principal goal was to reform and replace the Hanzi (ideographic) writing system.' Many of the literary giants and social activists - the conscience of the Chinese intelligentsia, notably Ba Jin (巴 金 1904-), Cai Yuanpei (蔡元 培), $\mathrm{Hu}$ Yuzhi (胡俞之, better known among Esperantists as Hujucz), Lu Xun (魯迅), and Ye Laishi (葉籟 士) 一 were active enthusiasts who used their free time, each in their own way, promoting Esperanto to young people, giving private tuition in some amateur adult learning center, or translating works from or into Esperanto. At various times in the history of the People's Republic, Esperanto was taught at the university, at local amateur adult learning centers, or via distance learning through the mailing of learning materials supported by national/regional radio and television broadcast. It has always had the blessing and ideological support from within the highest echelons of the CCP under Chairman Mao Zedong (毛澤 東) and Premier Zhou Enlai (周 恩 來) (see Hou and Zhou 1999). Mao, for example, was quoted as saying "if (one can) use Esperanto as form, and use it to advance the causes of internationalism and real revolution, then Esperanto may be learned, and should be learned" “如果以世界語爲形式, 而載以真正國際主義之道, 真正革命之道, 那麼世界語是可 以學的, 是應該學的>' (cited in Hou 1999: 204, my translation; cf. Forster 1982: 255). ${ }^{8}$ In addition, Esperanto has been recognized as one of the 
languages meeting the second foreign language (i.e. L3) requirement in qualifying exams for state cadres (Hou and Zhou 1999: 281), and there is government funding to run radio and TV programs.

Why has there been such a strong appeal among the intelligentsia in mainland China, especially those who identified with communism (via Marxism-Leninism) as an ideal sociopolitical model for China? The answer lies in the fact that staunch advocates of communism increasingly recognized the need to communicate with peoples outside of China, and quickly found English unsuited for this purpose: it was notoriously difficult for Chinese learners to master; it was loaded with culture-specific meanings; above all, it was the native language of the imperialists. Esperanto has none of these attributes, which makes it an ideal international auxiliary language. In 1986, China hosted the seventy-first annual Universala Kongreso (Esperanto congress) in Beijing, which was attended by 2,482 Esperantists (Hou and Zhou 1999: 4). This was followed by the first conference on the teaching of Esperanto (第一屆亞洲世界語教學㸴會), which was held in Nanning, Guangxi, in 1989 and attended by over 40 Esperantists (Hou and Zhou 1999: 279). Between 1983 and 1998, an estimated 3,000 Chinese mainlanders passed Esperanto tests/exams at the intermediate and advanced levels (Hou and Zhou 1999: 281). Toward the end of the twentieth century, the Esperanto movement in China was again active. This is indicated by the publication of at least three monographs: one a translation documenting the early efforts of the artificial language movement (Drezen 1999), another one documenting the historical background of the Esperanto movement in China (Hou 1999), and a third in honor of the contributions of the prominent Chinese Esperantist Hujucz (Hou and Zhou 1999). Notwithstanding these efforts, both the Esperanto movement and research on interlinguistics - the theoretical discipline that informs and promotes the use of artificial languages such as Esperantoin China are confronted with many obstacles, so much so that there seems little room for optimism as to the prospects of the promotion of Esperanto in China.

\section{Esperanto as a world language: problems and prospects}

With all its linguistic elegance and simplicity, relative acquisitional ease and merits, plus projected gains in language education and international communication (Humblet 1984; Richmond 1993a), and despite UNESCO's recognition and national support in a country like China, one can't help wondering why Esperanto has not been able to exert greater influence as a preferred auxiliary language after over 110 years of use and 
dissemination. It was this intriguing question which started me thinking: What does it take to be a world language?

Apart from political upheaval in twentieth-century Europe and complex ideological conflicts among the rank-and-file Esperantists, including Zamenhof himself (Forster 1982; Large 1985), perhaps the greatest obstacle toward a wider and more successful dissemination of Esperanto is the fact that, being an artificial language, Esperanto is assigned communicative functions artificially, rather than being a language that emerged after speakers have discovered a need for it in their natural communication. Another way of putting it would be to say that language functions normally precede language structures, rather than the other way around. ${ }^{9}$ This may be illustrated using examples of language emergence and language loss. Pidgins are prototypical examples of the former type in sustained language contact situations, where there is a need for getting one's meaning across when communicating with interlocutors who have no shared languages in common. It is true that in colonial societies, pidgins might take on a "social indexicality" function by virtue of being regarded as "the new index of status and social mobility" (Mühlhäusler 1996: 83), and had such negative associations as "forced labour, forced cultural change, displacement, racism and colonial exploitation" (Mühlhäusler 1996: 102), but pidgins may also serve practical functions such as the following:

1. offering a linguistic solution to potentially difficult problems of intercultural communication;

2. helping their users to adapt to externally introduced culture and change;

3. becoming languages of travel, excitement and opportunities; and

4. becoming languages of solidarity and self-identification. (Mühlhäusler 1996: 102)

Many of these functions are, for example, clearly visible in highly situationspecific and goal-oriented interactions between two distinct social groups in today's Hong Kong market place (more popularly known as the 'wet market') - Cantonese-speaking food vendors and English-speaking Filipino domestic helpers - where both pidgin Cantonese and pidgin English are blended smoothly and intricately for quick, transactional communication purposes. Over time, pidgins may develop into creoles when there are sufficient speakers using it as a first language, and when the communicative functions have been progressively codified and mapped onto more or less discrete structures, leading to the gradual emergence of a grammar.

The function-before-structure principle is also true of language loss. The demise of Latin as a living language is one classic example. Following 
the downfall of the Roman Empire, the vitality of Latin was gradually eroded, to the point of losing or ceding all its communicative functions to the regional vernaculars which we now call (Latin's daughter) languages. It should be noted that Latin continues to be learned in many parts of Europe, but to the extent that no communicative functions have been found for it, there is little hope of revitalizing it as a living language. ${ }^{10}$ Likewise, Brosnahan (1963, cited in Mühlhäusler 1996: 18) noted that, following the decline of Genghis Khan's Mongolian empire, the Turkish language rapidly disappeared "as soon as the instrumental reason to use it was gone." A third, contemporary example of language loss may be found in Taiwan, where linguists and scholars are reportedly striving to preserve the languages of various Aboriginal tribes. These risk disappearing largely because urbanization and a lack of ethnocultural awareness on the part of young members of Aboriginal populations work hand in hand, leading to a gradual language shift from Aboriginal languages (e.g. Amei, Bunung) to mainly Min (more popularly known as Minnan hua, 'the southern Min vernacular') and Mandarin. The prospects of language maintenance, according to the Taiwanese scholar reporting this at a conference (Huang 2001), are dim mainly because young members of Aboriginal groups are reluctant to use the language of their forefathers and parents for everyday communication, despite the current government's efforts to promote ethnic identities through education (a clear reversal from an intolerant, hegemonic national language policy from the late 1940s to the late 1970s in favor of the two dominant languages). ${ }^{11}$ To the Aboriginal populations in Taiwan today, linguistic human rights appear to be less a matter of concern, understandably it seems, when a person is fully preoccupied with making a living and doing what it takes to survive. As Mühlhäusler (1996: 322) observes, "[l]anguages are not so much lost as a result of speakers' or planners' intentions, but as a result of the loss of their non-linguistic support system." The examples above illustrate clearly, I think, that for a language to acquire and maintain its vitality, being able to use it for a broad range of meaningful communicative functions in natural settings is a prerequisite. Until this happens - on a fairly large scale - the prospect of elevating a planned language like Esperanto to a language of wider communication seems far from promising.

An extension of the previous argument is the degree of perceived usefulness of a second/foreign language. Advocates of Esperanto argue that, thanks to the characteristic of being easily adapted to local, culturespecific meanings, there is practically no limit as to the kinds of genre in which one wants to communicate in Esperanto, from literary genres such as poetry (original or translated) to academic writing (e.g. conference papers at the annual congress), from theatrical performance (e.g. Molière's Le Mariage Forcé) and comics (e.g. Astérix le Gaulois) to promotional 
flyers of interest groups such as chess clubs and philatelic societies (Forster 1982: 88; Tonkin 1987; Richmond 1993c). From the language learner's point of view, however, the pool of information written in Esperanto, in comparison with that of other languages of wider communication, remains small and often difficult to access. ${ }^{12} \mathrm{~A}$ similar observation may be found in Andrew Large's (1985) book The Artificial Language Movement, in which he traces the history and development of various artificial language projects to the present, including Esperanto. Towards the end of the book, Large points out the main 'damper' of the Esperanto movement as follows:

Languages have been spread by political and military power (Latin through the Roman Empire, Spanish and Portuguese in central and South America, Russian in Eastern Europe), by economic activity (English throughout the world in the present and previous centuries), by religion (Arabic in the Middle East and North Africa), by the arts and sciences (Latin, Greek, English and many more) and more recently, by tourism (especially English). Such powerful vehicles of dissemination are not available to any artificial language. It begins with the initial disadvantage that it is artificial: it is not the first language of any group of people (other than those few who may have learnt it in the cradle from enthusiastic parents). It cannot therefore build upon a homogeneous body of speakers; rather its speech community is scattered throughout the world. . The task of winning large-scale support around the world is formidable. Even a language such as Esperanto, which has achieved some modest success, has failed to attract people who are primarily looking for an international language to use. (Large 1985: 198f.)

Another damper is that, at the governmental level, "there are no political, economic or cultural pressures emanating from one or more states to learn the language" (Large 1985: 198f.)

In terms of language choice, with the exception of situations where a predominant language is imposed (as is typical of colonial societies), the choice of one second or foreign language over another hinges essentially on the perception of how useful the target language is. Social prestige is certainly one relevant factor; there may also be learners who choose to learn a language for subjective reasons, such as its perceived 'beauty' and aestheticism. Overall, however, it seems safe to assume that the choice is usually based on some subjective measure of what one can do with the target language. In this regard, I think there is still a long way to go before Esperanto can aspire to be a serious contender of English and meet the expectations and needs of prospective language learners. It may be true that, unlike other artificial, planned languages, Esperanto is fulfilling three important language functions in various Esperanto communities - being an instrument of communication, thought, and information exchange (D. Blanke 1989: 68) - but in terms of the range of communicative functions, the number of learners conversant in the target language, as well 
as the amount and variety of information encoded in that language, there is still a huge gap between Esperanto and English. With some knowledge of English (among other languages of wider communication such as Chinese and French), one could read about or into a wide range of topics, general or specialized, surf on the web to discover the diversity and novelties of most of what one is interested in, communicate one's needs for transactional purposes while traveling in many parts of the world, pick up information on the radio or TV, exchange information and views with others coming from different native language backgrounds, and so forth. All of these may arguably take place in Esperanto, too, but not to an extent that would make Esperanto an attractive alternative to English as an international language. Finally, the worldwide predominance of English today may have been due historically to such closely related deplorable factors as the expansion of the Empire, greed, conquest, and colonization, but these considerations are remote in the consciousness of contemporary language learners who are eager to improve their life chances in terms of acquiring "upward and outward mobility" (So 1992) in the age of the internet and globalization.

It should be clear by now, I think, that the arguments presented here are based essentially on a supply-cum-demand analysis, a market-oriented stance that ethically conscious and 'transcendental' social critics so loathe (Skutnabb-Kangas 2000). But it is my contention that such language learning motivations of the man, and woman, in the street are real and cannot be wished away by covering our eyes, ears, and mouths (I have in mind that famous satirical representation of the three monkeys symbolizing someone not wanting to see, to hear, and to talk about things which are unpleasant). As Saul Levin has pointed out:

At bottom, Esperanto is like socialism in seeking to remedy an evil through a radical change in the system: Let society as a whole accept a certain plan, based upon a set of principles that stand to reason, and it will achieve a great improvement over the irrational ways that unprogressive people have been clinging to. But again and again such optimistic theoretical plans run up against the intractable complexity of human behaviour. (Levin 1993: 3f.)

Part of Levin's "intractable complexity of human behaviour" includes, I think, the individual's choice of a second/foreign language based on what one can do with it. This helps explain why, for example, following radical sociopolitical changes in China in the past two decades leading to a sustained, robust economic growth, improved living conditions, and promising business opportunities, the number of learners of Mandarin Chinese (Putonghua) as a foreign language has increased steadily worldwide, to 
the point where a national examination board was established in Beijing to test and certify the learner's level of Chinese proficiency, much like what TOEFL or IELTS does to second/foreign language learners of English. One recent development is that eleven Putonghua teachers from China were sponsored by the British government to teach Chinese in secondary schools as part of an attempt to meet the growing demand for Chinese language instruction in the U.K. (Kazer 2001). Kazer, the bylined journalist of that news story in the South China Morning Post, notes that "[t]he rise in interest in Putonghua instruction is a reflection of China's growing importance on the world stage. That is increasingly evident in a wide range of areas - from business to politics to culture." The British Consulate General in Shanghai was also quoted as saying that "Chinese is the fastest growing foreign language in the UK . . . There is a growing recognition of China's huge significance in the next decades. . . . We need to have more China studies. We want to bring this into the secondary sector." where (Li 2002) I have outlined the macrohistorical background of the former British colony Hong Kong to show that the spread of English does not follow the same pattern everywhere in the world (cf. Fishman 1996), and that Hong Kong Chinese parents eager to have their children educated in English cannot be explained away as victims of linguistic imperialism or the hegemonic control of English in the Gramscian sense of the term. ${ }^{14}$ Instead, I argue that the general attitude of Hong Kong Chinese towards English is more appropriately characterized as a "love-hate complex," for, while English clearly has "enfeebling" aspects in terms of all kinds of psychological unease and frustration it brings about in the process of learning and using it, its "enabling" aspects cannot be denied. A similar point is made by Crowley (1996) in his critique of the centripetal forces hailing "standard spoken English" as a monologic force of authority at the expense of heteroglossia (Bakhtin 1981) and linguistic diversity in nineteenth-century Britain: "It may be that Gramsci's theory of hegemony is just too consensual, that in fact there is a conflictual aspect to this process" (Crowley 1996: 179-180). Pennycook (2000: 114) also points out that "implying that choices to use English are nothing but an ideological reflex of linguistic imperialism . . . lacks a sense of agency, resistance, or appropriation," and that "[a]ny concept of the global hegemony of English must therefore be understood in terms of the complex sum of contextualized understandings of local hegemonies" (Pennycook 2000: 117, emphasis added; cf. Ricento 2000b). In short, the dominant pattern of linguicism that has been convincingly demonstrated in many former British and American colonies in Africa and Asia (Phillipson 1992) does not apply to Hong Kong so well — not without some significant modification which 
takes into account the macrohistorical and sociopolitical background of Hong Kong (cf. Pennycook 1994, 1998). In fact, what motivated me to examine the relevance of the notions of linguistic imperialism and hegemonic control of English to the former British colony of Hong Kong is the observation that in both Phillipson's (1992) and Pennycook's (1994, 1998) theoretical deliberations, the demand for English by local inhabitants of postcolonial (and to some extent, colonial) societies has been left out of the picture (cf. Boyle 1997), whence the argument that without this important missing piece, the puzzle is incomplete.

\section{Why English?}

In a book I borrowed from the City University library, entitled The Discovery of Society by R. Collins and M. Makowsky (1998), I found a sheet of A4 paper hand-written with English words scattered all over, roughly as in Figure 1 (grid added):

\begin{tabular}{|c|c|c|c|c|}
\hline mundane & grime & tenement & respire & indignant \\
\hline hypocrisy & substructure & superstructure & & \\
\hline doomed & orthodoxy & bizarre & episode & \\
\hline culmination & idealist & & & \\
\hline manifest & facet & doctrine & & \\
\hline $\begin{array}{c}\text { bureaucratic vs. } \\
\text { autocratic }\end{array}$ & forgery & embroil & resolved & \\
\hline communism, & radical & proletarian & & \\
socialism & & & & \\
\hline abdicate & hitherto & tramp & opiate & \\
\hline extol & frugality & epoch & incipient & \\
\hline discern & ideological & animosity & malaise & \\
\hline axiom & stagnant & imperialism & per se & \\
\hline disenchantment & & & & \\
\hline
\end{tabular}

Figure 1. Vocabulary words found in a sheet left inside the book The Discovery of Society (Collins and Makowsky 1998) borrowed from the library of City University of Hong Kong 
It doesn't take an expert in forensic linguistics to tell that the words in Figure 1 represent a subset of vocabulary which the reader found useful to retain, probably for understanding a book like Collins and Makowsky's (1998), which is an excellent introduction to the field of sociology in the western world as well as a detailed outline of the historical background and thoughts of eminent, influential social thinkers from Plato to Goffman. A few of the vocabulary words are arguably indispensable for making sense of social science studies in general, such as ideological, orthodoxy, proletarian, superstructure, the words ending with the suffix -ism, and a word like opiate, which is often cited in the famous quotation attributed to Karl Marx, namely, "religion is the opiate of the poor." Users of the book are mainly teachers and students at City University, but it seems safe to assume that the word list was the property of a student - probably a Hong Kong Chinese student - who left it in the book by accident before I picked it up.

In Hong Kong, there are thousands of students like this anonymous reader who pursue higher education, mainly in the medium of English, ${ }^{15}$ and who need to make an effort to understand field-specific vocabulary words such as those in the word list above. Now, from the ethical point of view, one could deplore this state of affairs and consider this an example of linguicism. Indeed, there is much truth in the allegation that a lot of pain and frustration are engendered in the process of learning a content subject of their choice in English. ${ }^{16}$ But suppose the student aspires one day to do something similar to what we are doing - for example, to critically reflect on and debate about the desirability of English-dominated curricula in ESL settings - what alternative does that eager student have other than to make an effort to enhance his/her English vocabulary, and to develop a high level of English language proficiency, especially in academic English, say, enough to understand and respond to the real danger of linguistic genocide as a result of the spread of English and the eloquent plea for linguistic diversity worldwide in that book written by an engaged and leading author in the field (Skutnabb-Kangas 2000), who chose to publish that monumental work in her fifth language, English? To students with that kind of motivation and aspiration in mind, I would have no problem telling them: 'No pain, no gain.'

It has been observed that human language is unique as a semiotic system in that it is the only system which may be used to talk about itself, that is, to talk about language using metalanguage. And, as William Mackey (1967) has pointed out, one crucial indicator of the vitality and power of a language is to be found in the volume of works written in that language. Herein lies an important clue, I think, to one paradox which seems to have been overlooked in works on English linguistic imperialism, discourses of 
colonialism, and linguistic genocide to date, namely, the 'mediumas-message paradox.' Briefly put, to make known one's critique of the phenomenal spread of English, it is ironically English which commands the greatest potential to reach out far and wide to a global audience. As André Martinet observes in his introductory note to Klaus Schubert's (1989a) edited book Interlinguistics: Aspects of the Science of Planned Languages, "[w]ere the vocabulary of Esperanto closer to international usage, the present volume would not have to be written in English in order to secure the diffusion it deserves" (Martinet 1989: 3). Likewise, Large (1985) points out that the French government's long-standing policy to challenge and shun English led to her isolation: "it must be admitted that the French themselves, for so long at the forefront of the battle against English hegemony, now seem to be faltering, precisely because a refusal to use English is isolating them from international developments" (Large 1985: 195). A desire to be read by as many colleagues and researchers in the field as possible, therefore, seems to be one compelling reason why French scientists tended to decide to publish in English (Large 1985). A decision to publish in English, in turn, has the inevitable consequence of enhancing its vitality and power vis-à-vis other languages.$^{17}$ In effect, the more critical works of this kind are published and referenced in English, the more this generates a demand for a high level of English language proficiency among non-native speakers of English - a level high enough, for example, to appreciate the critique of, and to apprehend the threat of linguistic genocide (Skutnabb-Kangas 2000) posed by the phenomenal spread of English worldwide. The medium-as-message paradox is arguably what prompted Phillipson (2001b: 2) to deny his 'native speaker' identity when giving a conference paper bashing global English, in English: "My reluctance [to call myself a native speaker] has more to do with the fact that I am well aware that the mythology of the native speaker of English has been exported worldwide, to the point where a blind faith in the supposed attributes of the native speaker teacher species permeates much of the ideology of English learning worldwide." Phillipson's critique of the native-non-native distinction in the realm of ELT is well taken (cf. Phillipson 2000: 98, cf. 1992). What remains unclear to me is whether there exists value-free terminology which would help express the functional difference between people who learn a language as mother tongue or first language, as distinguished from others who learn it as a(n) second/foreign/ additional language (compare, e.g., 'medium of instruction' and 'medium of teaching and learning,' the latter seems to be gaining in currency in critical studies recently).

The same argument may be extended to practically every field of specialization: the specialized information that is currently available in Esperanto is not significant enough to allow Esperantists to further their field-specific 
inquiries and investigations exclusively in Esperanto (Levin 1993). This presents a catch-22 kind of problem: to attract more people, especially governments, to adopt Esperanto as an additional language in the school curriculum, one needs to be able to use Esperanto for a broad range of communicative functions, such as being able (a) to do things in the medium of Esperanto like watching a movie or singing a song of one's liking, (b) to search for and read into information on a topic of one's interest, and above all, (c) to use it spontaneously in natural communicative situations with fellow Esperantists, but more importantly, with shopkeepers, taxi drivers and so forth for everyday transactional purposes at home or overseas. And yet, for all of these to happen, the number of people who are literate and conversant in Esperanto must have reached a critical mass, failing which there will be little impetus on the part of Esperantists to contribute creative works in Esperanto - compared with doing it in English or some other language of wider communication. A very similar observation was made by I. A. Richards, the author of Basic English:

The root criticism of any revived or artificial language, however well designed, is that the immediate incentive which would make enough people learn and use one is lacking. . . We may all wish that everyone would learn such a language. But these wishes, however strong they might be, will never be strong enough to make enough people put enough time into learning an artificial language as a speculative investment. If you are going to the trouble of learning a language you need to feel that you will get a return for your toil this very year. A man may plant an orchard and wait six years for his apples; but six months is long enough to wait for verbs and prepositions to bear fruit. You do not want access merely to a limited and artificial literature, or to a few other speakers and correspondents. You want a vast and undelayed expansion of your contacts. The feeling that you are contributing in your small way to an idealistic but doubtful future is an inadequate motive. It is sad, but it is so. The realisation that the speakers of any artificial language are unlikely to increase as rapidly as the inhabitants, say, of Madagascar is a fatal damper. (Richards 1943: 11; cited in Large 1985: 200)

Not only is there a lack of incentive to learn Esperanto, it is also very difficult to attract serious and active researchers to study interlinguistics. Liu (1998) reviews the historical development of the Esperanto movement and the prospects of the study of interlinguistics in China, and notes that one of the four major hurdles is lack of scholars in the field of interlinguistics:

In present-day China it is ... difficult to find people who are willing to be professional linguists: there is a general preference for occupations which offer the chance to make money quickly. If linguistics itself cannot become financially attractive, interlinguistics will have to wait even longer for attention! Today, each person's worth is judged by the size of his wallet. Such an atmosphere makes it very difficult 
to found an interlinguistic study group. Yet without great human organizational resources, the depth and scope of interlinguistic research will inevitably be limited. (Liu 1998: 83)

What is true of China is probably true of many other parts of the world. If that is indeed the case, there seems little room for optimism regarding the prospects of Esperanto as a serious contender of English competing for the role of an international auxiliary language. It is not clear to me how one can break the spell of English and make the two things happen more or less simultaneously or in tandem: (a) to broaden the range of communicative functions of Esperanto, to the point where new learners would consider Esperanto useful and practical on a par with other natural languages in terms of the kinds of things that they can do with or in it; and (b) to raise the number of speaker-users of Esperanto to a critical mass, to the point where specialists in various fields who are literate and conversant in Esperanto are willing to publish and do other creative works in Esperanto. A leading Esperantist noted that "[e]very Esperanto propagandist knows by experience that outsiders hardly reject Esperanto for its linguistic defects, but mostly because it is of little use due to small numbers of users, and less often for its alleged cultural inferiority to the natural languages" (cited in Large 1985: 201).

One consequence of the medium-as-message paradox is a perceived lack of credibility of research on Esperanto and the claims made by Esperantists:

$[\mathrm{K}]$ nowledge of Esperanto tends to disqualify the researcher from studying it: to know Esperanto is to be regarded as an enthusiast, and hence biased; not to know it obviously disqualifies the researcher from writing about it ... . Hence the opportunities for outsiders to get to know the language and its community well are severely restricted. Such ignorance in turn makes the claims of Esperanto speakers - about the extent of the Esperanto movement, the efficacy of the language, or its role in international life - incredible, because they cannot be verified through the testimony of reliably objective scholars. (Edwards 1986; paraphrased by Tonkin 1993: 12).

A similar view may be found in Levin's (1993) "unbiased" (Richmond 1993a) article entitled 'Can an artificial language be more than a hobby? The linguistic and sociological obstacles':

In a fundamental way Esperanto is practically unlearnable. It lacks what is needed for normal acquisition of a language: embodiment in actual, accessible discourse to serve as a model for speaking and writing. Esperanto has failed to become a real vehicle of communication ... [N]o way has been found either to have a 
community adopt them [Esperanto grammar and vocabulary] and make them operate as a language, or to build a community upon such an artificial language ... [Learners of Esperanto are] not a community whose way of life is bound up with a certain language. (Levin 1993: 1) ${ }^{18}$

\section{Discussion and conclusion}

In a collection of conference papers written in defense of Esperanto, the editor Ian Richmond (1993a) boldly included a critique of the Esperanto movement (Levin 1993), which he considered "the best-expressed and most unbiased arguments against learning Esperanto" that he had ever come across (Richmond 1993a: ix-x). As Richmond explains in the foreword, the rest of the book is intended to be a response to that critique. After going through all the chapters, however, I must say that the bulk of the book has not quite achieved the goal of putting Levin's criticisms to rest. The main points raised in defense of the Esperanto movement are as follows:

(a) Esperanto may be an artificial language, but to the extent that it is currently being used by over 10 million Esperantists as an active, living language in many parts of the world, Esperanto should not be ignored by any serious study of the humanities and social sciences within academia;

(b) The claim that Esperanto lacks cultural values because it is no one's L1 is untrue; many literary works in Esperanto, original or translated, attest to the fact that Esperanto is easily adapted to local cultures (cf. Hou 1999; Hou and Zhou 1999);

(c) The allegation that Esperanto is incapable of expressing genuine thought is also unfounded, for there already exist many creative works in Esperanto representing a broad range of literary genres; and,

(d) Contrary to a popular misconception, Esperanto is no threat to the learners' ethnic identities, for the whole point of its raison d'etre is to serve the purpose of an auxiliary language in the international arena, rather than to undermine the vitality and functions of any local languages.

These are all valid and fairly well-substantiated counterarguments. But in my view, with regard to the core criticism, which may be glossed as 'who would want to learn a language with so few and limited communicative functions?', has not been adequately addressed, at least not satisfactorily.

Globalization may not be a welcome socioeconomic development for humankind, for, where it prevails it arguably favors the rich and 
aggravates the plight of the poor by perpetuating an unequal distribution of wealth and power. The biggest losers are those who do not have access to linguistic and cultural capital (Bourdieu 1991) as a stepping stone to moving up the social ladder, for example, to know enough English and to master a certain level of computer and information technology (possibly through English) to be on the right side of the digital divide. However, is it true, and just, to attribute all the social evils engendered by globalization to the spread of English? I'm not sure. Such a putative causal relationship seems overstated..$^{19}$ There are at least three other factors which have played no less an important role leading to an economically unjust industrialized world as we know it today: (a) the growing mobility and free flow of business information and investment capital as a result of advances made in computer and information technology, notably the internet; (b) increasing mechanization as manifested in the growing popularity of robots and machine-mediated services in various industries, with the depressing consequence of layoffs and jobs being increasingly taken away from humans; and above all, (c) the ever-expanding influence and global development of what Scollon and Scollon (1995) call the "Utilitarian Discourse System" at the expense of other discourse systems.

Tracing the ideological roots of capitalism and free trade - now practiced on a global scale - to the Enlightenment in England, the Scollons give a succinct account of how the writings of Adam Smith (1723-90), Jeremy Bentham (1748-1832) and John Stuart Mill (1806-73), among others, have exerted tremendous impact on a range of what many would regard as preferred or 'normal' practices in many parts of the world today, for example:

(a) the general prevalence of the so-called C-B-S communication style ('clarity,' 'brevity,' and 'sincerity') in such varied "forms of discourse" as the press release, the newspaper article, the sales presentation, the job interview, and academic writing, ${ }^{20}$

(b) the general view that creative and inventive talents as manifested in technological innovations are considered valuable for society and therefore should be encouraged through some generous reward system; and

(c) the widely shared belief that quantitative forms of measure such as census taking, market surveys, and opinion polls are seen as effective and reliable means of gauging what the people think with regard to specific issues.

Following Bentham's philosophy of 'utilitarianism,' the Scollons call such a discourse system the "Utilitarian Discourse System," the ideological roots of which are summarized below (Scollon and Scollon 1995: 104): 
(1) 'Good' is defined as what will give the greatest happiness for the greatest number;

(2) Progress (toward greater happiness, wealth, and individuality) is the goal of society;

(3) The free and equal individual is the basis of society;

(4) Humans are defined as rational, economic entities;

(5) Technology and invention are the sources of societal wealth;

(6) Creative, inventive (wealth-producing) individuals are the most valuable for society; and,

(7) Quantitative measures such as statistics are the best means of determining values. ${ }^{21}$

There is arguably some ideological affinity between the Utilitarian Discourse System and Phillipson's favorite metaphor in his critique of English-driven globalization: McDonaldization. This term was coined by the sociologist George Ritzer (1991) in his most successful and popular book The McDonaldization of Society to refer to "the culmination of a series of rationalization processes that had been occurring throughout the twentieth century" (Ritzer 1995: 130). It was motivated by a critical analysis of what Ritzer (1991) regards as a 'paradigm case' — McDonald's - which bears all the five components of the rationalization process that come to characterize more and more institutions in modern and postmodern societies such as fast food restaurants and credit cards: calculability, efficiency, predictability, substitution of nonhuman for human technology, and irrationality of rationality (Ritzer 1995: 133-134). These five components of the rationalization process are clearly related to, and may be regarded as a recent development of, the Utilitarian Discourse System. As for the critique that McDonald's, with its golden arches, is a highly visible, quintessential symbol of all the social evils of 'cultural imperialism' wreaking havoc in the guise of globalism or globalization, the anthropologist James Watson (1997a, 1997b, 1997c, 2000) finds it misleading and inaccurate. In a conscious attempt "to situate the global in the local" (Watson 1997a: ix), Watson together with four other colleagues produced "ethnographic accounts of McDonald's social, political, and economic impact on five local cultures" (Watson 1997a: 6): Beijing, Hong Kong, Taipei, Seoul, and Japan. The findings led Watson to the following market-oriented observation:

McDonald's could not have succeeded in East Asia without appealing to new generations of consumers - children from 3 to 13 and their harried, stressed-out parents. No amount of stealth advertising or brilliant promotions could have done the trick alone. The fast-food industry did not create a market where none existed; 
it responded to an opportunity presented by the collapse of an outdated Confucian family system. In effect, McDonald's tailgated the family revolution as it swept through East Asia, first in Japan and Hong Kong (1970s), then in Taiwan and South Korea (1980s), and finally in China (1990s). There is no great mystery here, unless one is predisposed to seeing imperialist plots behind every successful business. (Watson 2000: 4)

As Watson (1997b, 1997c, 2000) further points out, two of the keys to McDonald's success are (a) its readiness to go to great lengths to localize its operational procedures, from finding local food suppliers and personnel to respecting local customers' cultural values and practices (e.g. serving vegetable McNuggets, and mutton-based Maharaja Mac to Hindu and Muslim customers in India), and (b) its innovative ideas appealing to increasingly affluent East Asian families, notably parents and children. One strategy which has proved immensely successful, especially with single-child families in China where children are referred to as 'little emperors and empresses,' is a special birthday party package — complete with gifts and toys for all participants, and an appointed hostess leading the children in songs and games. At the same time, McDonald's is seen by different groups of customers as "home away from home" largely because many customers' homes are crowded and unsuited for social gatherings. This helps explain why many students treat McDonald's as a youth club where they can chat, study, or play while snacking, while retirees come to enjoy reading newspapers and/or chatting with neighbors. As Watson observes, "[b]oth retirees and students are attracted by the roomy tables, good light, and air-conditioning - a combination not easily found in Hong Kong, Beijing, or Shanghai. In effect, local citizens have appropriated private property and converted it into public space" (Watson 2000: 6). Also, parents whose children frequent McDonald's have little to worry about because, apart from clean (though not necessarily healthy) food and high standards of public hygiene, smoking is banned and no alcoholic beverages are served, making McDonald's an unfriendly place for drug addicts and gangsters. The rich ethnographic details above clearly demonstrate that what McDonald's means to local customers in East Asia is a far cry from what is envisioned by supporters of the theory of 'cultural imperialism.' As Watson concludes using Hong Kong as example: "[p]eople are not the automatons many theorists make them out to be. Hong Kong's discerning consumers have most assuredly not been stripped of their cultural heritage, nor have they become the uncomprehending dupes of transnational corporations" (Watson 2000: 8).

In addition, the worldwide prevalence of the Utilitarian Discourse System helps account for a host of recent sociopolitical developments in 
China, such as its accession to WTO largely out of its own initiative, and the consensus reportedly reached among the top Communist Party leaders under Jiang Zemin (Kwan 2001), that "advanced productive forces" or entrepreneurs who successfully amassed capital and who managed to create jobs and make a positive contribution to the nation's economic growth should be honored and invited to join the Party. One important implication of this latest development is that the Chinese Communist Party no longer represents solely the interests of the proletariat. The Utilitarian Discourse System arguably also prevails in metropolitan cities like Hong Kong, whose survival and economic well-being increasingly hinge on the local peoples' abilities to meet the professional and vocational needs of various service industries in a so-called 'knowledge-based economy.' In view of the global economic downturn threatening the well-being and survival of many, and given the uncertainty clouding the projected merits that Esperanto might bring, it is doubtful whether promoting Esperanto at the expense of English would be a sensible language policy to pursue.

Within the academic circles of ethically conscious social critics and critical sociolinguists, in particular through the writings of engaged scholars such as Phillipson (1992, 1994, 1997, 1998, 2000, 2001a, 2001b) and Skutnabb-Kangas (2000), the Esperanto movement has taken on a more assertive mission of countering English linguistic imperialism. But personally I think the prospects are dim, mainly because, except for those learners who are motivated by ideological reasons, there are relatively few communicative functions that could be realized with Esperanto, and few things that could be done in Esperanto - in terms of both the learner's receptive and productive linguistic competence. I think this is the main reason why it has been so difficult for Esperanto to attract more learners, which in turn makes it difficult for the number of Esperantists to grow to a critical mass, hence a vicious circle. To quote Saul Levin (1993) once more:

For thousands of years, one language after another has been spread through conquest, control, and settlement of additional territory; but the spread of English in the last three centuries is due still more to capitalism. The growing wealth and enterprise of Great Britain and the United States made the language highly useful or quite indispensable to millions of others; they have been attracted to it by self-interest. And the laissez-faire approach to the hardship of language barriers will continue to operate for the benefit of English. (Levin 1993: 4)

In sum, in the foreseeable future at least, advocates of Esperanto will continue to be fighting an uphill battle. As it has been pointed out, to tip the balance now in favor of English, nothing short of some social engineering campaign or radical social change in the form of national language policy on a global scale would be necessary (e.g. many national governments 
putting in concerted efforts to add Esperanto to, or even substitute Esperanto for, English in their local school curricula) - if Esperanto is to rival, if not replace, English as a language of wider communication. Arnold Pitt rightly diagnosed that "[p]erhaps the strongest rivalry [between English and Esperanto] is for room on the crowded curricula of the world's schools" (The planned and the ethnic 1987: 19; cf. Large 1985: 97). As one of the measures to "strengthen a principle of equality in communication" in multilingual settings and "to fight for a better linguistic world order," Phillipson (2001b: 19-20) appeals for the gradual introduction of Esperanto in meetings and internal documents between representatives of member states of the European Union and Commission. He believes that "Esperanto tends to be rejected out of ignorance rather than serious consideration of how it could counteract linguistic hierarchies and facilitate and strengthen multilingual communication" (Phillipson 2001b: 20, cf. Phillipson 2000). In a sense, this study may be regarded as a response to his call for a careful scrutiny of the problems and prospects of Esperanto as a possible contender of English for the role of a world language. Having done that, I am afraid I have to conclude that, even if one is sympathetic to the cause, given the lack of individual incentive to learn it for reasons discussed above, and the absence of a compelling need for local governments to add Esperanto to the already crowded school curriculum, I find it difficult to share Phillipson's and Skutnabb-Kangas's optimism and to heed their advice to support a pro-Esperanto policy worldwide.

\begin{abstract}
Afterword
Notwithstanding my queries of Esperanto as a possible substitute for English as an international auxiliary language, I do not mean to belittle Robert Phillipson and Tove Skutnabb-Kangas's fine contributions to advancing the global cause of linguistic human rights. On the contrary, I have great respect for their scholarly work and conscientious efforts. My main purpose in this paper is not to find fault in their work, but to assess the feasibility of one of the lines of action that they advocate, namely, to promote Esperanto to the status of an international auxiliary language, which in their view is one way to counter the hegemony of the de facto world language, English. It is my wish that this paper could stimulate Esperantists and other scholars of linguistic human rights to address the question, what does it take for Esperanto to be a likely candidate to replace English as an international auxiliary language.
\end{abstract}




\section{Notes}

1. An earlier draft of this paper was presented at the International Conference, 'Anglophone Cultures in Southeast Asia: Appropriations, Continuities, Contexts' at the Chinese University of Hong Kong, October 8-11, 2001. I am grateful to Prof. Braj Kachru for his comments on the conference draft. I alone am responsible for any inadequacies that remain.

2. In this paper, the term 'world language' is used interchangeably with three other closely related terms: 'international language,' 'global language,' and 'language of wider communication.'

3. For Esperantists, the designation 'planned language' is preferred to other similar terms such as 'international language,' 'auxiliary language,' 'artificial language,' and 'world language.'

4. For a linguistic description of word formation and lexical grammar in Esperanto, see Large (1985: 112-117) and Schubert (1989b).

5. See Forster (1982: 375-378) or Large (1985: 202-205), both 'Appendix I,' for a detailed description of the morphosyntactic rules. Tonkin (1987: 275), however, cautions that "in reality the structure of the language was considerably more complex than could be contained in sixteen simple rules, not all of which could in any case be described as rules of grammar."

6. If we compare this mission entrusted to Esperanto by some of its adherents today with the function assigned to it when Esperanto was first created, there seems to have been a shift in its raison d'être. As is well known, Zamenhof was determined to create a sufficiently simple artificial language in the hope of facilitating intergroup communication largely because he was disheartened by the fact that speakers of four distinct native languages - Russian, Polish, German, and Yiddish - belonging to different ethnic groups in Bialystok, his birthplace in Poland, hated and refused to talk to each other, which to him was the main cause of misunderstanding and conflicts, sometimes leading to bloodshed much to his regret (see e.g. Large 1985: 71f, 179). In the idealist's design, therefore, the primary function assigned to Esperanto was to serve as an additional, non-exclusionary auxiliary language for the purpose of facilitating interethnic communication and promoting fraternity and intergroup harmony, rather than to use it, in an exclusionary manner, to curb the hegemony of a predominant language by supplanting its functions as an international lingua franca (cf. Forster 1982).

7. See Forster (1982), Ch. 7, 'External relations: Socialism and Esperanto'; cf. Large (1985).

8. Piron's (1989: 159) observation that Mao Zedong, like other national leaders such as Stalin, Hitler, and Chiang Kai Shek, "prohibited the teaching of Esperanto" and "imprisoned and, often, physically liquidated the active members of the Esperanto movement," is probably true of the Cultural Revolution period (1967-1976), when leading Esperantists, like other intellectuals with overseas connections, had to put up with one form of public humiliation or another (e.g. 'shame parade').

9. Cf. Odlin's (1989) use of the terms 'function' and 'structure' in his book Language transfer: "In this book, the term structure is roughly synonymous with the term tagmeme, a unity of form and function (. . .). In other words, nothing is a structure unless it has both a form (some definite pattern) and a function (some definite use)" (Odlin 1989: 31).

10. One famous attempt to revitalize Latin as an international auxiliary language was made by Giuseppe Peano during the first two decades of the 20th century: Latino sine flexione, later renamed Interlingua. It consisted of a radically 'minimized' Latin grammar and a core vocabulary based on English, French, German, Spanish, Italian, Russian, Greek, and Sanskrit (see Large 1985: 143-145). 
11. In other words, 'outside agents' (Skutnabb-Kangas 2000) did play an important role leading to the current state of affairs, where the stakeholders - the minority groups of Aboriginal descent - are now indifferent and have to be persuaded to see in their ethnic languages an important part of their ethnic and cultural heritage.

12. The search for literature on Esperanto in the process of writing this paper is a case in point. Skutnabb-Kangas's (2000: 735-36) book, for instance, includes a list of references on Esperanto studies written in various languages, including Esperanto, but many of the references, including those in English, are difficult to get hold of in Hong Kong (cf. Schubert 1989a; Tonkin 1993).

13. As is well-known, Phillipson (1992) is skeptical of such exchange programs, regarding them as the norm-providing countries' linguicist national policy in disguise. That skepticism is partly justified here, for part of the Sino-British exchange funds (over $£ 300,000$, with an additional contribution from HSBC, Hongkong \& Shanghai Banking Corporation) are used to bring 40 British university graduates to China to work as English teaching assistants in middle schools. And, although the agreement purportedly supports British students (50 in 2000; 180 in 2001) to learn Chinese language and culture through summer camp activities in China, it is conceivable that they are also expected to play the role of active agents facilitating the spread of English there (Kazer 2001).

14. One of the important theoretical constructs behind the notions of linguistic imperialism (Phillipson 1992) and discourse of colonialism (Pennycook 1998) in the post-colonial era is Antonio Gramsci's concept of hegemonic control. There is a bit of irony, however, that Gramsci himself was utterly opposed to Esperanto as a universal language. In a letter written to a comrade, Leo Galetto, in 1918, Gramsci was quoted as saying "[d]own with Esperanto . . . a linguistic form that is rigidified and mechanized. I am a revolutionary, a 'historicist,' and I affirm that only those forms of social activity - whether linguistic, economic, or political - that arise spontaneously from the activity of free social energies are 'useful and rational.' Therefore: down with Esperanto, as well as with all the privileges, all the mechanizations, all the definitive and rigidified forms of life...." (Germino 1990: 28). In a footnote on the same page, Germino notes: “Gramsci's article 'La lingua unica e l'Esperanto,' February 16, 1918, in LCF, 668-673, had ridiculed the idea of a contrived universal language such as Esperanto." (Original source: Gramsci, Antonio. [1982]. La città futura, 1917-1918. Ed. by Sergio Caprioglio. Turin.)

15. It should be noted that English in Hong Kong is learned as an additional language, and that Cantonese-English bilingualism in no way threatens the well-being and development of Cantonese (Li 2000, 2002).

16. Here I am reminded of a reflective remark made by one of my former teachers of English, a Caucasian American who had been teaching English in Hong Kong for over fifteen years when I was an undergraduate student at Chinese University. Reflecting on her career as an ESL teacher, she said it dawned on her one day how fortunate it was that Caucasians like herself were not required to study in Chinese.

17. This indexical function of English probably underlies Berns et al.'s (1999) observation that part of the 'power' of Phillipson's (1992) book is indexed by the fact that it was "published by an international publisher of the stature of Oxford University Press" (Berns et al. 1999: 140).

18. Levin further made an interesting contrast between Esperanto and Hebrew, the latter being successfully revived - no accidental feat but the culmination of many years of preparation and practice among Zionists in the Hebraist circles in Europe: "Both Esperanto and the movement to restore Hebrew grew out of the same milieu, the Jewish intelligentsia of eastern Europe, dissatisfied with the ancestral religion — more precisely 
that part of the intelligentsia which was also dissatisfied with the Yiddish language and not willing to settle for Russian, Polish, or German either. Zamenhof himself had been deeply interested in Hebrew ... . In retrospect, the Hebraist circles in Europe, with all their newspapers, poems, and novels, were merely preparation and practice for what developed into an organic language community in Israel. Esperanto, however, is still stuck in that preparatory phase, as a hobby of those who believe in it" (Levin 1993: 6; for parallels between Esperanto and Hebrew, see Wood 1979).

19. This point has been acknowledged by Phillipson himself: "The expansion of English in recent decades has occurred simultaneously with a widening gap between haves and have-nots, and with a consolidation of wealth and power globally in fewer hands. I am not suggesting a direct causal link between English and processes of global enrichment and impoverishment, but to suggest that the two are not connected, which is basically Crystal's (1997) position, seems to me to be irresponsible" (Phillipson 2000: 90).

20. Interestingly, Scollon and Scollon (1995) point out that, in practice, the C-B-S communication style is sometimes not observed in the very textbooks where it is presented as an axiom.

21. See Chapter 6 of Scollon and Scollon (1995), for more details.

\section{References}

Bakhtin, Mikhail (1981). The Dialogic Imagination. Austin: University of Texas Press.

Berns, Margie; et al. (1998). (Re)experiencing hegemony: the linguistic imperialism of Robert Phillipson. Review of Robert Phillipson 1992. International Journal of Applied Linguistics $8(2), 271-282$.

—; et al. (1999). Hegemonic discourse revisited. International Journal of Applied Linguistics 9(1), 138-142.

Blanke, Detlev (1989). Planned languages - a survey of some of the main problems. In Interlinguistics: Aspects of the Science of Planned Languages, K. Schubert (ed.), 63-87. Berlin and New York: Mouton de Gruyter.

Blanke, Wera (1989). Terminological standardization - its roots and fruits in planned languages. In Interlinguistics: Aspects of the Science of Planned Languages, K. Schubert (ed.), 277-292. Berlin and New York: Mouton de Gruyter.

Bourdieu, Pierre (1991). Language and Symbolic Power. Cambridge: Polity Press.

Boyle, Joseph (1997). Imperialism and the English language in Hong Kong. Journal of Multilingual and Multicultural Development 18(3), 169-181.

Brosnahan, L. F. (1963). Some historical cases of language imposition. In Language in Africa, J. Spencer (ed.). Cambridge: Cambridge University Press.

Collins, R.; and Makowsky, M. (1998). The Discovery of Society, 6th ed. Boston, MA.: McGraw Hill.

Crowley, Tony (1996). Language in History: Theories and Texts. London and New York: Routledge.

Crystal, David (1997). English as a Global Language. Cambridge: Cambridge University Press.

Drezen, Ernst K. (1999). Shìjiè gòngtóngyǔ š̌ sän ge shijì de tànsuǒ [History of world language: three centuries' quest], Chinese trans. M. Xu. Beijing: Shangwu. Original edition, 1931.

Edwards, Jane (1993). Esperanto as an international research context. In Aspects of Internationalism: Language and Culture, I. M. Richmond (ed.), 21-34. Lanham, MD: University Press of America. 
Fishman, Joshua A. (1996). Introduction: some empirical and theoretical issues. In Post-imperial English: Status Change in Former British and American Colonies, 1940-1990, J. A. Fishman et al. (eds.), 3-12. Berlin and New York: Mouton de Gruyter.

Forster, Peter Glover (1982). The Esperanto Movement. Contributions to the Sociology of Language 32. The Hague, Paris, and New York: Mouton.

Germino, Dante (1990). Antonio Gramsci: Architect of a New Politics. Baton Rouge and London: Louisiana State University Press.

Hou, Zhiping (1999). Hujucz kaj Esperanto [Hu Yuzhi yǔ shìjièy̆ 'Hu Yuzhi and Esperanto']. Beijing: China Esperanto Publishing.

—; and Zhou, Guoxiang (eds.) (1999). Shìiièyǔ zài Zhōngguó yībăinián [Hundred years of Esperanto in China]. Beijing: China Esperanto Publishing.

Huang, Lillian M. (2001). Teaching of minority languages in Taiwan elementary schools. Paper presented at the international conference 'Plurilingual Hubs in the New Millennium,' The Polytechnic University of Hong Kong, January 9-12, 2001.

Humblet, Jean-E. (1984). The language problem in international organizations. International Social Science Journal 36, 143-155.

Kachru, Braj B. (1985). Standards, codification and sociolinguistic realism: the English language in the outer circle. In English in the World: Teaching and Learning the Language and Literatures, R. Quirk and H. G. Widdowson (eds.). Cambridge: Cambridge University Press.

- (1996). World Englishes: agony and ecstasy. Journal of Aesthetic Education 30(2), 135-153.

Kazer, William (2001). Putonghua teachers imported to spread word in Britain. South China Morning Post, September 21, p.10.

Kwan, Daniel (2001). Jiang wins support for broadening party base. South China Morning Post, September 27, p.11.

Large, Andrew (1985). The Artificial Language Movement. Oxford and New York: Blackwell.

Levin, Saul (1993). Can an artificial language be more than a hobby? The linguistic and sociological obstacles. In Aspects of Internationalism: Language and Culture, I. M. Richmond (ed.), 1-8. Lanham, MD: University Press of America.

Li, David C. S. (2000). Phonetic borrowing: key to the vitality of written Cantonese in Hong Kong. Written Language and Literacy 3(2), 199-233.

- (2002). Hong Kong parents' preference for English-medium education: passive victims of imperialism or active agents of pragmatism? In Englishes in Asia. Communication, Identity, Power and Education, A. Kirkpatrick (ed.), 29-62. Melbourne: Language Australia.

Liu, Haitao (1998). Interlinguistics in China. Language Problems and Language Planning 22(1), 76-87.

Mackey, William F. (1967). Bilingualism as a World Problem. Montreal: Harvest House.

Martinet, André (1989). The proof of the pudding. . Introductory note. In Interlinguistics: Aspects of the Science of Planned Languages, K. Schubert (ed.), 3-5. Berlin and New York: Mouton de Gruyter.

Mühlhäusler, Peter (1996). Linguistic Ecology: Language Change and Linguistic Imperialism in the Pacific Region. London and New York: Routledge.

Odlin, Terence (1989). Language Transfer: Cross-linguistic Influence in Language Learning. Cambridge: Cambridge University Press.

Pennycook, Alastair (1994). The Cultural Politics of English as an International Language. London: Longman.

-(1998). English and the Discourses of Colonialism. London: Routledge.

- (2000). English, politics, ideology: From colonial celebration to postcolonial performativity. In Ideology, Politics and Language Policies: Focus on English, T. Ricento (ed.), 107-120. Amsterdam and Philidelphia: John Benjamins.

Phillipson, Robert (1992). Linguistic Imperialism. Oxford: Oxford University Press. 
-(1994). English language spread policy. International Journal of the Sociology of Language $107,7-24$.

-(1997). Realities and myths of linguistic imperialism. Journal of Multilingual and Multicultural Development 18(3), 238-248.

-(1998). Globalizing English: are linguistic human rights an alternative to linguistic imperialism? Language Sciences 20(1), 101-112.

- (2000). English in the new world order: variations on a theme of linguistic imperialism and 'world' English. In Ideology, Politics and Language Policies: Focus on English, T. Ricento (ed.), 87-106. Amsterdam and Philidelphia: John Benjamins.

-(2001a). Global English and local language policies. Language Problems and Language Planning 25(1), 1-24.

- (2001b). English in the new world order: going beyond national and corporate linguistic imperialism. Paper presented at The Nigerian Millennium Sociolinguistics Conference, Lagos, August 16-18, 2001.

Piron, Claude (1989). Who are the speakers of Esperanto? In Interlinguistics: Aspects of the Science of Planned Languages, K. Schubert (ed.), 157-172. Berlin and New York: Mouton de Gruyter.

The planned and the ethnic (Interview with Arnold Pitt). (1987). English Today 8, 18-19.

Ricento, Thomas (2000). Ideology, politics and language policies: introduction. In Ideology, Politics and Language Policies: Focus on English, T. Ricento (ed.), 1-8. Amsterdam and Philidelphia: John Benjamins.

Richards, I. A. (1943). Basic English and Its Use. London: Kegan Paul, Trench, Trubner.

Richmond, Ian M. (ed.) (1993a). Aspects of Internationalism: Language and Culture. Lanham, MD: University Press of America.

- (1993b). Esperanto: a tool for international education. In Aspects of Internationalism: Language and Culture, I. M. Richmond (ed.), 57-66. Lanham, MD: University Press of America.

- (1993c). Esperanto translation and cultural specificity. In Aspects of Internationalism: Language and Culture, I. M. Richmond (ed.), 85-102. Lanham, MD: University Press of America.

Ritzer, George (1991). The McDonaldization of Society. Thousand Oaks, CA: Pine Forge Press.

-(1995). Expressing America: A Critique of the Global Credit Card Society. Thousand Oaks, CA: Pine Forge Press.

Sadler, Victor (1989). Knowledge-driven terminography for machine translation. In Interlinguistics: Aspects of the Science of Planned Language, K. Schubert (ed.), 311-335. Berlin and New York: Mouton de Gruyter.

Schubert, Klaus (ed.) (1989a). Interlinguistics: Aspects of the science of planned languages. Berlin and New York: Mouton de Gruyter.

- (1989b). An unplanned development in planned languages. In Interlinguistics: Aspects of the Science of Planned Languages, K. Schubert (ed.), 249-274. Berlin and New York: Mouton de Gruyter.

Scollon, Ron; and Suzanne Scollon (1995). Intercultural Communication: A Discourse Approach. Oxford, UK and Cambridge, MA: Blackwell.

Skutnabb-Kangas, Tove (2000). Linguistic genocide in education - or worldwide diversity and human rights. Mahwah, NJ and London: Lawrence Erlbaum Associates.

-; and Robert Phillipson (1986). Denial of linguistic rights: the new mental slavery. Paper presented at the XIth World Congress of Sociology, New Delhi, August 1986.

So, Daniel (1992). Language-based bifurcation of secondary education in Hong Kong: past, present and future. In K. K. Luke (ed.), Into the Twenty-first Century: Issues of Language in Education in Hong Kong, 69-95. Hong Kong: Linguistic Society of Hong Kong. 
Tonkin, Humphrey (1987). One hundred years of Esperanto: a survey. Language Problems and Language Planning 11, 264-282.

-(1993). Esperanto studies: an overview. In Aspects of Internationalism: Language and Culture, I. M. Richmond (ed.), 9-20. Lanham, MD: University Press of America.

Watson, James L. (ed.) (1997a). Golden Arches East: McDonald's in East Asia. Stanford, CA: Stanford University Press.

- (1997b). Transnationalism, localization, and fast food in East Asia. In Golden Arches East: McDonald's in East Asia, J. L. Watson (ed.), 1-38. Stanford, CA: Stanford University Press.

- (1997c). McDonald's in Hong Kong: consumerism, dietary change, and the rise of a children's culture. In Golden Arches East: McDonald's in East Asia. J. L. Watson (ed.), 77-109. Stanford, CA: Stanford University Press.

-(2000). China's big mac attack. Foreign Affairs 79(3), 120-134.

Wood, Richard E. (1979). A voluntary, non-ethnic, non-territorial speech community. In W.F. Mackey and J. Ornstein (eds.), Sociolinguistic Studies in Language Contact: Methods and Cases, 433-450. The Hague, Paris, and New York: Mouton. 
Copyright of International Journal of the Sociology of Language is the property of Walter de Gruyter \& Co. and its content may not be copied or emailed to multiple sites or posted to a listserv without the copyright holder's express written permission. However, users may print, download, or email articles for individual use. 